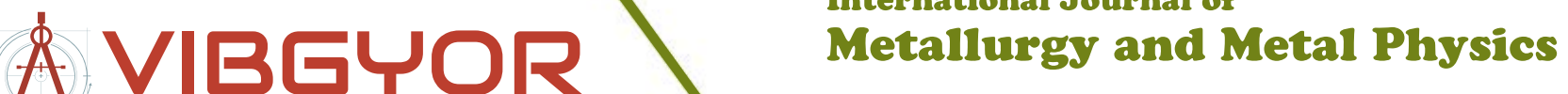

ISSN: 2631-5076

\section{A Critical Approach to the Biocompatibility Testing of Niti Orthodontic Archwires}

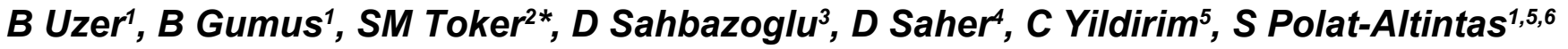 and $D$ Canadinc ${ }^{1,5}$}

\author{
${ }^{1}$ Department of Mechanical Engineering, Koc University, Advanced Materials Group \\ (AMG), Turkey \\ ${ }^{2}$ Department of Materials Engineering, California Polytechnic State University, USA \\ ${ }^{3}$ Department of Orthodontics, Hacettepe University, Turkey \\ ${ }^{4}$ Department of Oral and Maxillofacial Surgery, Ankara University, Turkey \\ ${ }^{5}$ Surface Science and Technology Center (KUYTAM), Koç University, Turkey \\ ${ }^{6}$ Department of Physics, Abant Izzet Baysal University, Turkey
}

\begin{abstract}
The biocompatibility of Nickel-Titanium (NiTi) archwires was investigated by simulating actual contact state of archwires around brackets, which enabled incorporation of realistic mechanical conditions into ex situ experiments. Specifically, archwires (undeformed, and bound to brackets on acrylic dental molds) were statically immersed in artificial saliva (AS) for 31 days. Following the immersion, the archwires and the immersion solutions were analyzed with the aid of variouselectron-optical techniques, and it was observed that carbon-rich corrosion products formed on both archwire sets upon immersion. The corrosion products preferentially formed at the archwire-bracket contact zones, which is promoted by the high energy of these regions and the micro-cracks brought about by stress assisted corrosion. Moreover, it is suggested that these corrosion products prevented significant $\mathrm{Ni}$ or $\mathrm{Ti}$ ion release by blocking the micro-cracks, which, otherwise, would have led to enhanced ion release during immersion. The current findings demonstrate the need for incorporating both realistic chemical and mechanical conditions into the ex situ biocompatibility experiments of orthodontic archwires, including the archwire-bracket contact.
\end{abstract}

\section{Keywords}

Biocompatibility, NiTi, Shape memory alloy, Orthodontic archwire, Stress-assisted corrosion

\section{Introduction}

Nickel-Titanium (NiTi) shape memory alloys continue to attract significant attention in medicine due to their superior shape memory and pseudoelastic properties, especially in the fields of cardiovascular surgery and orthodontics [1-4]. The pseudoelastic behavior stands out in dental applications: for instance, in the case of orthodontic archwires, the pseudoelastic property of NiTi makes the application of constant stress possible over large tooth displacements [1,2], which not only minimizes tissue damage during treatment [5], but also eliminates readjustment procedures - which are quite uncomfortable for the patients - required for archwires made of conventional materials, such as medical grade stainless steel [1,6-9]. Specifically, the austenite-to-martensite phase transformation above the austenite finish temperature $\left(\mathrm{A}_{\mathrm{f}}\right)$ and under straining beyond the elastic limit of the NiTi alloy leads to a state of constant stress, which is known as pseudoelasticity [10].

Despite their remarkable pseudoelastic capacity and wide utility in medical applications, the biocompatibility of NiTi alloys is still subject to debate, mainly due to potential $\mathrm{Ni}$ release, which can lead to serious health problems, especially in Ni-allergic patients $[11,12]$. It has been shown that, nickel hypersensitivity is one of the most commonly encountered adverse effects of NiTi archwires by orthodontists [12]. Specifically, Ni ions released into the intraoral cavity may cause complications, such as burning sensations and

*Corresponding author: SM Toker, Department of Materials Engineering, California Polytechnic State University, San Luis Obispo, CA 93407, USA, Tel: 1805-756 -6441, Fax: 1805-756 2-299, Email: mtoker@calpoly.edu

Received: December 07, 2015: Accepted: February 06, 2016: Published: February 09, 2016

Copyright: (C) 2016 Uzer B, et al. This is an open-access article distributed under the terms of the Creative Commons Attribution License, which permits unrestricted use, distribution, and reproduction in any medium, provided the original author and source are credited. 
inflammation around or in the mouth, and gingival hyperplasia [12]. Therefore $\mathrm{Ni}$ ion release is very critical in terms of determining the biocompatibility of NiTi archwires. The $\mathrm{Ni}$ ion release depends mainly on the applied stress state, and the type of body fluid (or tissue) the sample comes into contact with [11]. Specifically, it has been demonstrated that $\mathrm{Ni}$ ion release increases concomitant with both plastic deformation and acidity of the fluid $[11,13]$. Furthermore, the geometry of the sample has been demonstrated to play a vital role in the ion release behavior, where the corresponding surface finish and properties dictate the amount of ion release along with the fluid contacting the material [11]. Furthermore, hardness, topography and roughness were also showed to significantly influence the corrosion behavior and biocompatibility [14]. As for the effect of applied stress on the $\mathrm{Ni}$ ion release behavior, biocompatibility experiments featuring both static $[5,13]$ and cyclic $[15,16]$ loads on NiTi samples have been carried out, where the loading was restricted to simple three-point bending, which does not represent the actual stress state of archwires during clinical treatment.

The sliding mechanism, which is defined as the movement of the teeth and brackets along the archwire, plays also a significant role in achieving a successful and comfortable orthodontic treatment [17]. The effect of archwire surface hardness, topography and roughness on an efficient arch-guided tooth movement has been pointed out in numerous studies [14,18-20]. Specifically, the sliding mechanism is strongly influenced by the friction force present in the archwirebracket contact sites [20], which depends on the type of orthodontic archwire used for the treatment and its surface roughness [17]: the bracket slot roughness has a positive correlation with the frictional force and it adversely affects the smooth movement of teeth throughout the treatment [20]. In addition, the stresses developed at these contact sites can lead to further $\mathrm{Ni}$ ion release [11], and therefore, the roughness of archwire-bracket contact sites constitute one the most important parameters affecting the orthodontic treatment [20]. The archwire manufacturers aim to minimize the roughness of these sites in order to achieve a more efficient sliding mechanism $[17,20,21]$, and therefore the roughness of these sites have been analyzed in detail by mechanical testing of various archwire and bracket sets $[18,20,21]$. However, these testing methods fell short of simulating the realistic conditions of the chemical and mechanical contact conditions of exposure in the actual intraoral cavity. Thus, in order to reduce the friction force and attain an efficient sliding mechanism, the stress-assisted corrosion cracking (SCC) needs to be incorporated into the ex-situ experiments.

The importance of adopting a more realistic loading scenario becomes clearer once the possibility of SCC is realized, where applied stress enhances crack initiation on the surface, and then crack propagation from surface into the bulk in corrosive environments
[15]. In the case of NiTi alloys, the core of the material becomes exposed directly to the corrosive environment if the protective film that formed during the initial processing is damaged under applied stress, which leads to $\mathrm{Ni}$ release [22]. In addition, the chemically-, thermally- or stress-induced changes in the surface properties, such as surface roughness and morphology, promote crack initiation and/ or propagation due to dissolution [23-25].

Despite the findings forwarded on the $\mathrm{Ni}$ ion release and corrosion behavior of NiTi orthodontic archwires [5,11-13,15,16,2530], to the best of the authors' knowledge, an investigation focusing on the biocompatibility and $\mathrm{Ni}$ ion release behavior of $\mathrm{NiTi}$ alloys in the presence of SCC, and under realistic chemical and mechanical contact conditions has not been forwarded yet. The current work was undertaken with the motivation of addressing this issue, such that laboratory experiments closely simulating the actual clinical conditions were designed and carried out on commercially available $\mathrm{NiTi}$ orthodontic archwires. For this purpose, static immersion experiments were carried out in artificial saliva (AS) with the incorporation of mechanical contact of archwires and brackets. Specifically, NiTi archwires were subjected to AS for 31 days while attached to brackets fixated on upper dental arch mold model of an actual patient. This allowed for the simulation of the stresses that arise by the contact of wires with brackets and remain constant on the wire throughout the treatment with the alignment of the teeth owing to the pseudoelastic property of the archwire. Following the immersion experiments, both the NiTi archwires and AS solutions were inspected for changes in chemical content, and the surface properties of the tested archwires were carefully monitored. The outcomes of these analyses clearly demonstrate the necessity of simulating both chemical and mechanical contact within the intraoral cavity while carrying out laboratory experiments, for the sake of a realistic biocompatibility assessment.

\section{Materials and Methods}

The current work employed static immersion experiments in AS in order to investigate the stress-assisted corrosion-induced changes in the surface properties of and possible ion release from $\mathrm{NiTi}$ orthodontic archwires ${ }^{*}$ in intraoral cavity. Specifically, metal brackets ${ }^{*}$ were fixated to a dental mold model made of acrylic, and were bonded to the dental mold with light cure adhesive (3M Unitek Transbond XT).

In this study, the commercially available heat activated NiTi archwires with a chemical composition of $54.5-57 \mathrm{wt} \% \mathrm{Ni}$ [31] were utilized. The orthodontic archwires exhibit variety in their austenite finish temperatures $\left(\mathrm{A}_{\mathrm{f}}\right)$ depending on their chemical compositions or manufacturing processes [32]. The NiTi alloy utilized in the current study had an $\mathrm{A}_{\mathrm{f}}$ temperature ranging between $20-40^{\circ} \mathrm{C}$ [31]. The
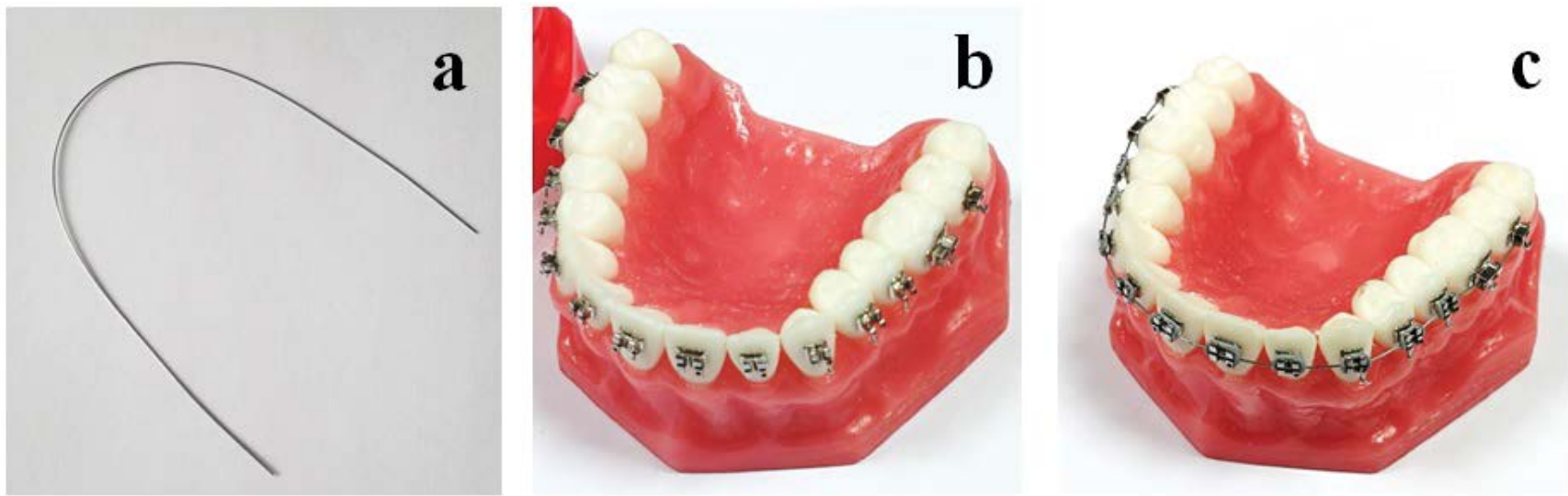

Figure 1: Three different experimental sets prepared for the immersion experiments: (a) UA: The underformed archwire, (b) B: The dental model with only brackets bonded on, and (c) BA: The dental model both with brackets bonded on andarchwire bound on the brackets. 
amount of force which moves the teeth throughout the orthodontic treatment was measured with three point bending test and found to be in a range of $0.6-1.0 \mathrm{~N}$ at $3 \mathrm{~mm}$ deflection [31]. The archwires were placed into the bracket slots with the following sequence: both bonding of the brackets and the binding procedure were performed from upper left second premolar to upper right second premolar. The NiTi archwire was bound conventionally with ligature wire. The archwire was inserted passively because there were no crowding or rotations on plaster models. This passive bound was found sufficient to simulate the aimed mechanical contact, since the NiTi wires used in the current study have the ability to retain at almost a constant stress throughout the alignment of the teeth during treatment, owing to their pseudoelastic properties. Three different sets of experiments were carried out to detect the amount of $\mathrm{Ni}$ ions released both from the archwire and the brackets individually, and each individual set was repeated for at least three times for the sake of reliability and statistical consistency. The first experimental set considered the immersion of the undeformed archwire only (UA) (Figure 1a), while the second set also included the dental model with only brackets bonded on (B) (Figure 1b).

'18' slot 3M Unitek Gemini Roth brackets and the corresponding metallic bases were manufactured from $17-4 P H$ and $304 \mathrm{~L}$ stainless steels, respectively.

"3M Unitek Smart Clip Nitinol heat activated archwires with $0.36 \mathrm{~mm}$ diameter were used in the experiments.

The third experimental set featured the dental model with the brackets, and the archwire bound on the brackets (BA) (Figure 1c). These sets were subjected to static immersion in AS for 31 days in separate containers and the released ions from each set were detected by Inductively Coupled Plasma-Mass Spectroscopy (ICP-MS). The ingredients and the $\mathrm{pH}$ value of the AS employed in the current work are presented in table 1. It should be noted that the $\mathrm{pH}$ of the natural saliva is about 7, however, a lower $\mathrm{pH}$ value (2.3) was preferred for AS in this study in order to incorporate the effects of acidic environment caused by possible dental plaque, and simulate the aggressive environment that would potentially stem from nutritional habits, and the corresponding organic depositions and intraoral microorganisms $[9,11,33]$. Moreover, as the protective titanium-oxide layer is expected to undergo degradation at $\mathrm{pH}$ values below 312 , the $\mathrm{pH}$ value of 2.3 was also suitable in terms of incorporating the effects of changes in oxide-layer characteristics during the exposure to AS. While preparing the AS, $1 \mathrm{M}$ of $\mathrm{HCl}$ was slowly added to the initial AS solution with $\mathrm{pH}$ value of near 7 until a level of acidity corresponding to a $\mathrm{pH}$ value of 2.3 was attained $[28,29,33]$. The prepared fluid was initially observed to be stable and remained the same throughout the experiments confirming the absence of salt deposition. Each model was immersed in a separate sealed beaker with $180 \mathrm{ml}$ of prepared AS. The immersed samples were kept in an electronically controlled

Table 1: Properties of the AS utilized in the current immersion experiments.

\begin{tabular}{|c|c|c|}
\hline Ingredients & Amount of Ingredients (g/l) & pH \\
\hline $\mathrm{NaCl}$ & 0.4 & \\
\hline $\mathrm{KCl}$ & 0.4 & \multirow{2}{*}{2.3} \\
\hline $\mathrm{CaCl}_{2} \cdot 2 \mathrm{H}_{2} \mathrm{O}$ & 0.906 & \\
\hline $\mathrm{NaH}_{2} \mathrm{PO}_{4} \cdot 2 \mathrm{H}_{2} \mathrm{O}$ & 0.69 & \\
\hline $\mathrm{Na}_{2} \mathrm{~S}_{9} 9 \mathrm{H}_{2} \mathrm{O}$ & 0.005 & \\
\hline Urea & 1 & \\
\hline
\end{tabular}

Table 2: ICP-MS operating parameters.

\begin{tabular}{|l|l|l|l|}
\hline Number of points per peak & 3 & Plasma gas flow (Argon) & $15 \mathrm{~L} / \mathrm{min}$ \\
\hline Replicates & 5 & Helium gas flow (Collision cell) & $4.3 \mathrm{ml} / \mathrm{min}$ \\
\hline Sweeps/replicate & 100 & Carrier gas flow (Argon) & $1 \mathrm{~L} / \mathrm{min}$ \\
\hline Total acquisition time & $41.900 \mathrm{~s}$ & Plasma Forward Power & $1550 \mathrm{~W}$ \\
\hline Integration time per mass & $0.12 \mathrm{~s}$ & & \\
\hline
\end{tabular}

water bath sustaining the temperature at $37^{\circ} \mathrm{C}$, corresponding to the body temperature.

Following an immersion period of 31 days, the immersed undeformed and bound archwires were comparatively investigated using scanning electron microscopy (SEM) and Energy dispersive X-ray spectroscopy (EDX) in order to detect SCC and the corresponding surface morphological changes, as well as to identify the elements deposited on the archwire and specifically on archwirebracket contact sites. Three samples were analyzed via SEM and EDX for each different condition. The SEM and EDX analyses were conducted on an SEM, where the SEM images were captured with a secondary electron detector at a magnification of $1000-5000 \times$, an accelerating voltage (EHT) of $5 \mathrm{kV}$, current of $30 \mathrm{pA}$ and a working distance of $11 \mathrm{~mm}$. The EDX results were obtained at an EHT of $10 \mathrm{kV}$ and current of $1000 \mathrm{pA}$. Surface topography and roughness of each archwire, and the sites in contact with the brackets on the archwires were analyzed by atomic force microscopy (AFM). The AFM images were recorded at a tapping mode in air utilizing an antimony $(\mathrm{n})$ doped silicon cantilever with a rotated tip with a radius of $8 \mathrm{~nm}$. The linear scanning rate was set as $1 \mathrm{~Hz}$ (1 line/s) and the surface topography of the materials was monitored on $30 \times 30 \mu^{2}$ scanning area.

The surface roughness results of the immersed archwires were compared with an as-is (as received from the manufacturer) archwire in order to better understand the corrosion induced roughness changes. Released Ni ions from the archwire and bracket sets in immersion fluids were detected with ICP-MS equipped with octupole reaction system helium collision cell for spectral interference removal, rather than ICP-OES, considering the $\mu \mathrm{g} / \mathrm{L}$ (ppb) level ion detection capability of the former. The ICP-MS was operated with Micro Mist glass concentric nebulizer, quartz Scott-type spray chamber and $\mathrm{Ni}$ sampler/skimmer cones. Daily instrumental optimizations were performed using $1 \mu \mathrm{g} / \mathrm{L}$ tuning solution for the short-term stability of the instrument. The corresponding instrument settings and parameters are provided in table 2.

\section{Results and Discussion}

The surfaces of the as-is NiTi archwire and, the archwires UA and BA which were immersed in artificial saliva for 31 days were investigated via SEM, EDX and optical microscopy following the immersion experiments and compared with the as-is archwire surface. The SEM images of the as-is, and UA and BA are presented in figure 2 and figure 3.

Figure 2 demonstrates that the as-is archwire features a relatively smooth surface, except for the processing marks and rare impurities,

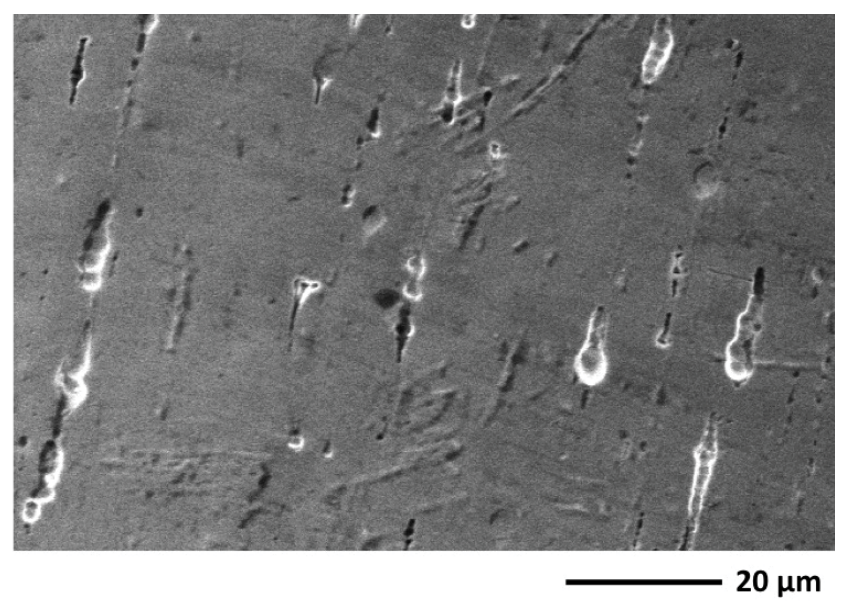

Figure 2: Representative SEM image of the as-is orthodontic archwire surface. 


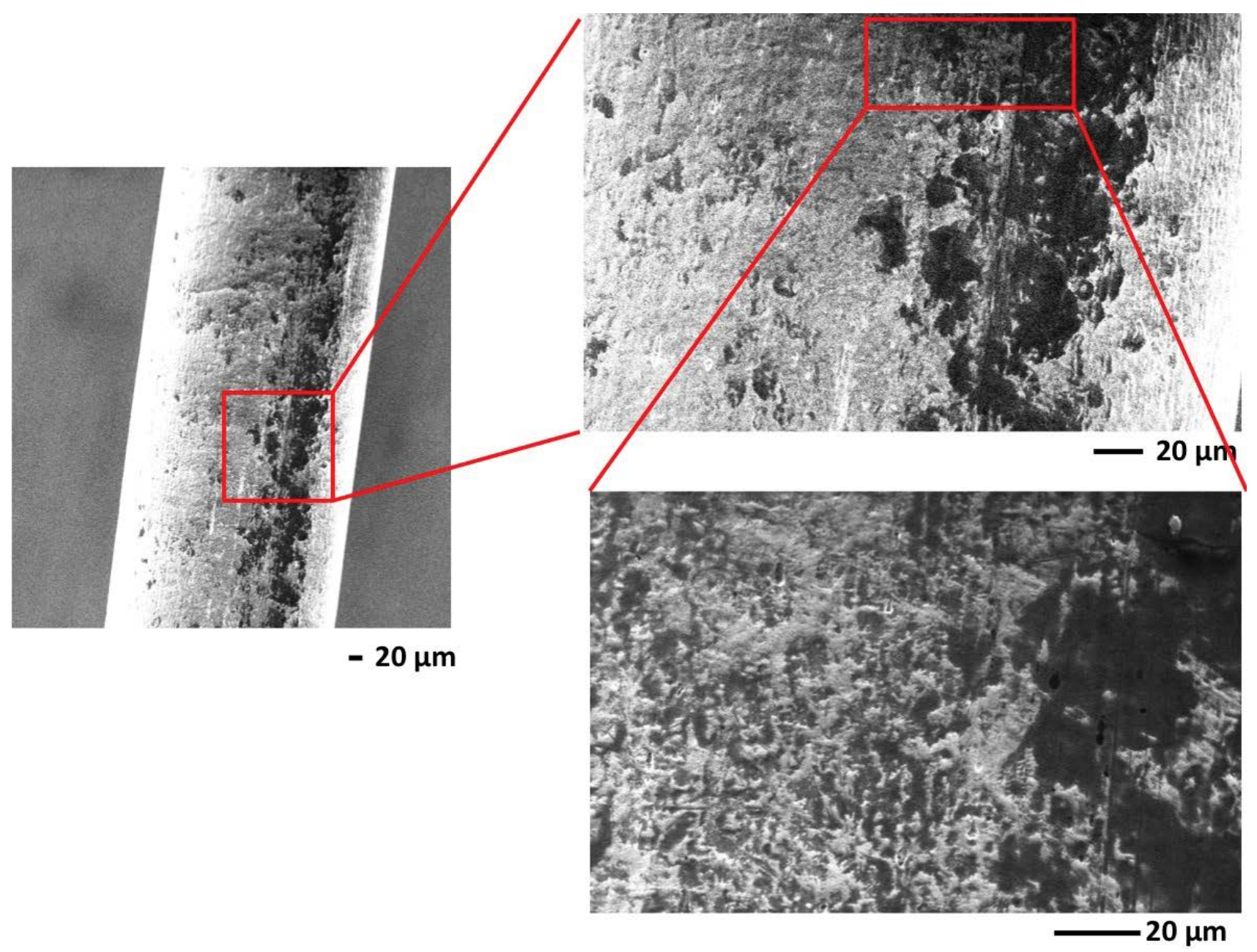

Figure 3: SEM images demonstrating $C$ deposition on the bound orthodontic archwire (BA) immersed in AS.

Table 3: Relative quantities of the elements (provided in wt.\%) detected by energy dispersive X-ray spectroscopy (EDX) on the as-is archwire, and new structures present on the archwires UA and BA which were immersed in AS for 31 days (Figure 3 and Figure 4). All the detected Ni and Ti quantities were found statistically significant with $\mathrm{P}<0.01$ for $\mathrm{UA}$ and $\mathrm{P}<0.001$ for $\mathrm{BA}$. (Elements with signals lower than 0.1 wt.\% were not included in the table.)

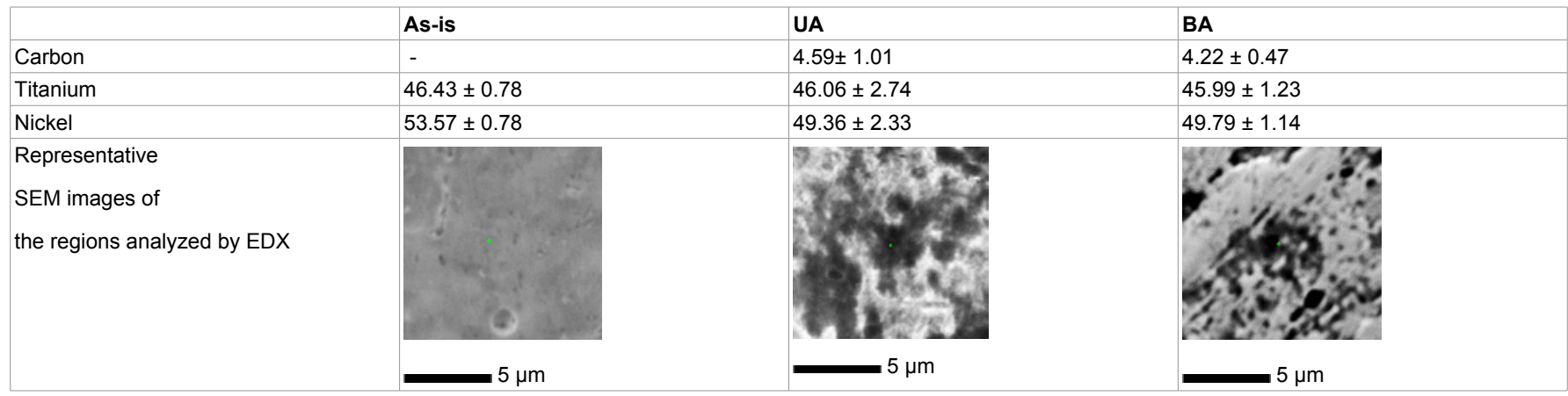

implying that any foreign particle observed on the UA surfaces must be new structures that formed upon immersion in AS.

The SEM images of the UA show rare dark spots which are randomly located on the archwire surface (Figure 4). Quantitative $\mathrm{EDX}$ analysis from these regions indicated that these dark spots are mainly C containing structures (Table 3 ). Considering the high $\mathrm{C}$ content of AS and the previous experience on the $\mathrm{C}$ deposition on NiTi upon immersion in AS $[9,11]$, it can be argued that the observed C-rich particle formation on the immersed undeformed NiTi archwires is reasonable. The random localization of these particles on the archwire surface stems from the uniformity of the archwire and the lack of distinctive and repetitive structures on the archwire surface. Specifically, the only available sites for nucleation of new structures were the impurities, which were randomly distributed on the archwire surface, leading to this observed random deposition of corrosion products.

The SEM examination of the archwire-bracket contact sites in BA also demonstrated presence of dark spots, which, however; were located with certain intervals on the surface rather than a random localization (Figure 3). Furthermore, each spot occupied a wider area (Figure 3) as compared to those observed on the immersed undeformed archwire (Figure 4). The quantitative EDX analysis indicated that these dark spots were also C-rich structures similar to those present on the UA (Table 3). In order to track the localization of all the corrosion products with certain intervals on the BA, the sample was also investigated with optical microscope, from which 


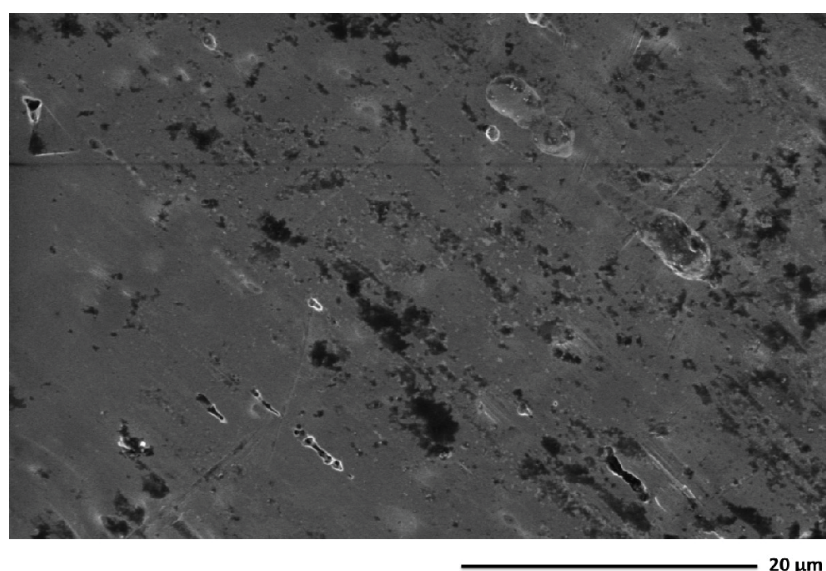

Figure 4: Representative SEM image of the undeformed orthodontic archwire (UA) surface immersed into AS.

Table 4: AFM Surface roughness measurements of the archwires.

\begin{tabular}{|c|c|c|}
\hline As-is & UA & BA \\
\hline $40.8 \mathrm{~nm}$ & $56.6 \mathrm{~nm}$ & $108 \mathrm{~nm}$ \\
\hline
\end{tabular}

several images were gathered together for a more comprehensive picture of the overall archwire surface (Figure 5).

The optical microscopy images clearly evidence the newly formed structures on the BA are located with almost equal intervals to each other (Figure 5). Moreover, measurement from the optical microscopy images demonstrates that the length of these intervals (about $1 \mathrm{~cm}$ ) is close to the average distance between the brackets bonded to two consecutive teeth on the mold. This result justifies that the new particles are mainly deposited around the archwire-bracket contact zones. This localized precipitation of corrosion products is in good agreement with the findings of a similar study that compared an as-is archwire immersed in AS with a companion archwire that was retrieved from a patient after exposure to actual intraoral conditions for the same time interval [9]. Specifically, C-rich structure formation was observed on both archwires, however; the depositions on the retrieved archwires, which were localized at the archwire-bracket contact sites, were dense enough to be visible to the naked eye. On the contrary, the deposition was random and observable only under SEM in the case of the immersed archwire [9]. This finding was attributed to the stress concentration induced by the contact of archwire and brackets, which created more available sites for the nucleation of corrosion products [9]. Similar observations were also madein a work where in-service SCC based fracture of NiTi archwires were examined [5]. Specifically, the microstructural and elemental analyses of the fracture surfaces showed that $\mathrm{C}$ rich products precipitated in the vicinity of the crack tip, which constituted one of the highest stress concentration sites on the archwire [5].

In order to better understand the SCC effect on the archwires their surface topography and roughness were analyzed by AFM. Figure 6 compares the surface topographies of the two different archwires: UA and BA. The latter possesses a surface with denser peaks and valleys, which stems from the SCC at the archwire-bracket contact sites. The average roughness $\left(\mathrm{R}_{\mathrm{a}}\right)$ values of each set are presented in table 4 . UA which was exposed to the corrosive environment of the AS for 31 days shows higher roughness value than the as-is archwire. On the other hand BA shows higher roughness value than the UA. This result shows that when the archwire is under the effect of both stress and corrosion its surface roughness increases more significantly. Moreover, the archwire-bracket contact site of the BA had the highest roughness value, which implies that the high energy regions create local higher roughness sites on the archwire surface, further contributing to the localized precipitation in these regions.

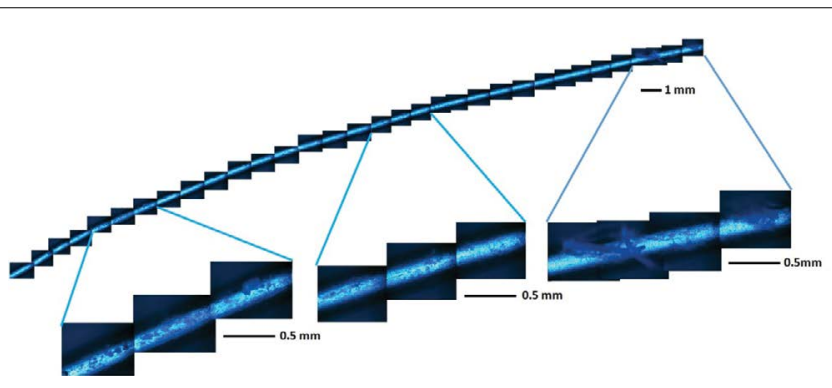

Figure 5: Optical microscope images of the bound orthodontic archwire (BA) immersed in AS Multiple high resolution images were gathered together to show the status of a meaningful segment of the wire upon being released from the mold.

Table 5: ICP-MS results demonstrating the Ni content released into the AS solutions used in the experiments.(The possible ion release from the ligatures on the brackets were considered as a part of the ion release from the brackets).

\begin{tabular}{|c|c|}
\hline Sample & $\begin{array}{c}\text { Ni }(\boldsymbol{\mu g} / \mathbf{L}) \text { release into the AS } \\
\text { solution }\end{array}$ \\
\hline Undeformed archwire(UA) & $0.750 \pm 0.150$ \\
\hline Dental model with only brackets bonded on(B) & $15.234 \pm 1.054$ \\
\hline $\begin{array}{c}\text { Dental model both with brackets bonded on } \\
\text { and archwire bound on the brackets(BA) }\end{array}$ & $26.539 \pm 2.517$ \\
\hline
\end{tabular}

The simulation of the actual state of contact between the archwires and the brackets, and the incorporation of the mechanical conditions into ex situ experiments provided more realistic surface roughness results. It should be noted that in order to speculate on the effect of the roughness on the sliding mechanism the dynamic forces created by mastication and the chemical condition of the intra oral environment also need to be included in the experiments. Thereby, the friction coefficient of these sites can be minimized more significantly to achieve a more efficient sliding mechanism and orthodontic treatment.

The preferential particle deposition at stress concentration zones have been subject to several studies, which evidenced that grain boundaries, impurities and other stress concentration points create ideal sites for nucleation of new phases, where the existing high energy facilitates precipitation of new structures by spending minimum energy $[34,35]$. Similarly, the current results showed that the $\mathrm{C}$ ions within the AS solution preferentially pile up in the form of C-particles on the archwire-bracket contact sites of BA which had the highest surface roughness value. The higher surface energy of these sites has further catalyzed the deposition of the corrosion products [11].

Moreover, a closer look into these sites demonstrated that the stress induced by the contact of the archwire with brackets causes formation of micro-cracks on the archwire surface as a result of SCC (Figure 7a). Specifically, the archwire surface becomes more prone to the stress created at the bracket contact sites due to the corrosive nature of AS, which enables crack initiation and propagation. Similar to the aforementioned stress concentration sites, cracks also constitute high energy regions, and thus, favor deposition of corrosion products in their close vicinity. Figure $7 \mathrm{~b}$ evidences that the precipitates preferentially nucleate around the cracks on the BA. This argument is further strengthened by the random localization of corrosion products on the surface in the absence of micro-cracks in the case of the UA, which was not loaded during the immersion period. Therefore, formation and localization of new particles at certain locations with almost equal intervals, which correspond to the archwire-bracket contact sites, can be explained with the stress concentration created at these contact sites due to SCC and the resulting micro-cracks. Yet, in contrast to the archwire that was exposed to actual intraoral conditions [9], the C-rich structures nucleated on the BA were not visible to naked eye. This difference can be attributed to the more complex composition and variable 
constituents of actual intraoral environment, which involves not only the saliva but also the nutrients that are specific to the patient, implying that eating habits of the patient also significantly influence particle accumulation on the archwires in actual clinical conditions.

For the detection of potential $\mathrm{Ni}$ ion release from the archwires into the AS solutions and to investigate the effect of SCC on the ion release behavior of the archwires, all the AS solutions were subjected to ICP-MS following the experiments. The Ni amounts measured in the three test solutions are presented in table 5. The amount of $\mathrm{Ni}$ ion release from the dental model with only brackets was higher than the $\mathrm{Ni}$ ion release from the UA. This result shows that significant amount of Ni has released from the brackets. On the other hand AS with BA had the highest amount of released $\mathrm{Ni}$ ions when compared with the other AS sets. It is remarkable that the amount of Ni ions in the AS with BA was more than the total amount of the $\mathrm{Ni}$ ions released from the UA and the brackets. This result verifies the fact that extra Ni ion had released due to SCC and resulting cracks in the archwires. Considering the critical limit of Ni intake $(0.12-0.5 \mathrm{mg} / \mathrm{L})$ the $\mathrm{Ni}$ contents of these $3 \mathrm{AS}$ solutions were far below this limit and therefore doesn't constitute toxicity for human body [30], indicating that the commercially available $\mathrm{NiTi}$ archwires can be considered safe for the patients within the immersion period considered in the current experiments. This finding also demonstrates that the archwire-bracket contact zones did not significantly enhance ion release despite being ideal sites for deposition of corrosion products. This can be attributed to the micron-size cracks promoted by SCC, which were not large enough to lead to significant ion release, in addition to becoming blocked by the deposited corrosion products, further preventing ion release. As the new particle nucleation preferentially takes place at the contact regions and in the vicinity of cracks, it is suggested that the ion release from these zones was prevented by the particles deposited on the cracks. Moreover, the ICP-MS results demonstrated that, although BA exhibited the highest amount of $\mathrm{Ni}$ ion release compared to $\mathrm{UA}$ and $\mathrm{B}$ as a result of the SCC induced by wire-bracket contact, the released amount is still lower than the critical value which can be toxic for the human body, due to the prevention of further ion release by the preferential precipitation of corrosion products at potential ion release sites such as cracks. This finding is in good agreement with previously forwarded evidence for reduction in ion release due to oxide layer deposition on the stressinduced cracks [13].

Another mechanism which can be critical for the Ni release of NiTi archwires in contact with brackets is galvanic corrosion. The introduction of new archwires and brackets with novel materials and designs into the orthodontics offers orthodontists a variety of choice in their combination [36]. Among these different combinations researchers aim to find the specific archwire-bracket combination providing the best treatment with the ultimate efficiency in the sliding mechanism [20]. When the selected archwire-brackets are composed of two different metals the contact of these two dissimilar metals can lead to galvanic corrosion in the existence of saliva [12,36,37]. However, previous analysis focusing on the galvanic corrosion of $\mathrm{NiTi}$ archwires demonstrated that different archwire-bracket combinations did not lead to significant Ni ion release [36]. Therefore, in the current study, galvanic corrosion was not considered as an effective mechanism for Ni release and was not separately analyzed. a)

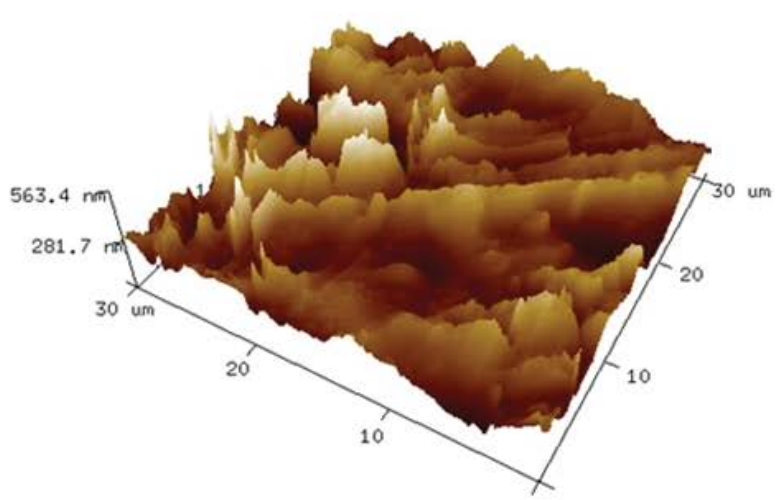

b)

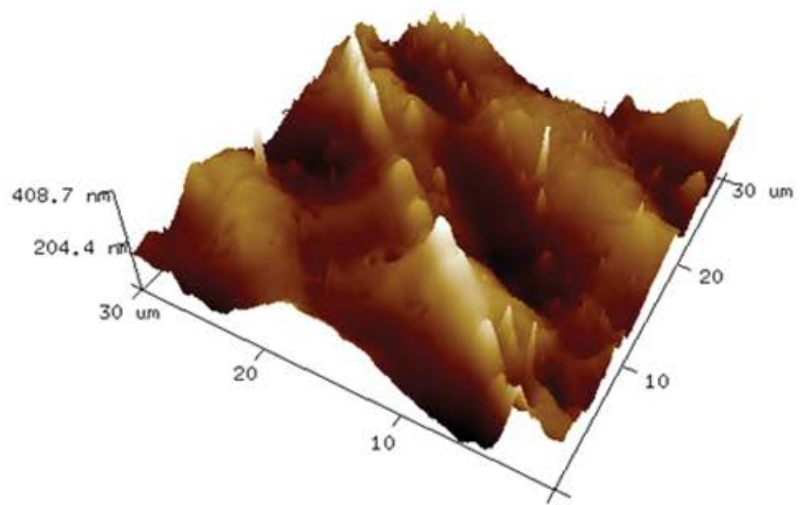

Figure 6: Surface topographies of the (a) underformed (UA) (b) bound archwire (BA)

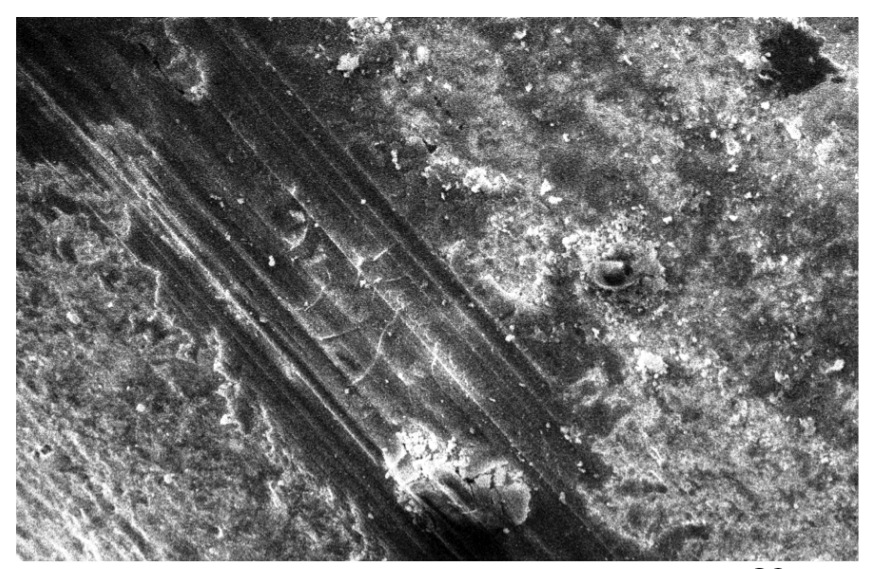

(a)

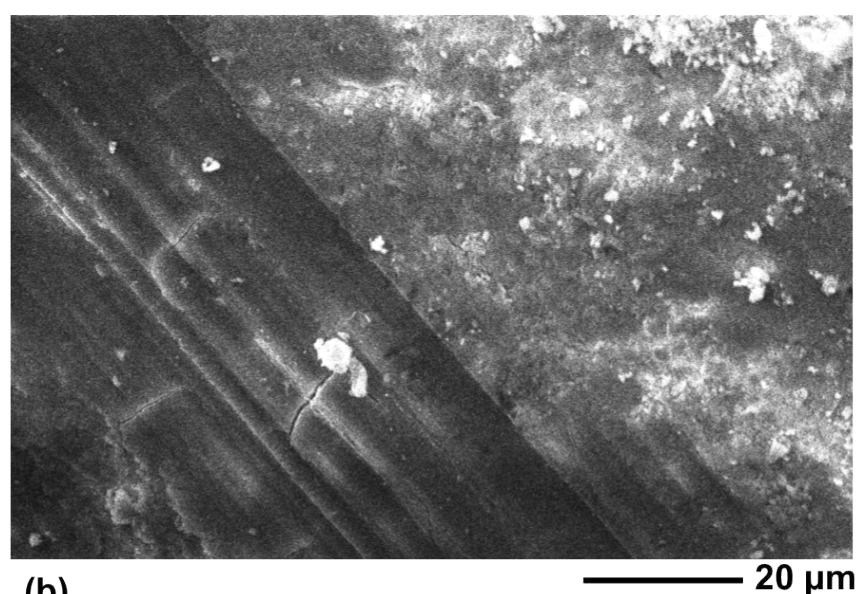

(b)
$20 \mu \mathrm{m}$

Figure 7: SEM images demonstrating (a) the crack formation due to SCC, and (b) the localization of the corrosion products near the cracks on the bound orthodontic archwire (BA) immersed in AS. 
Overall, the current results indicate that the stress concentration stemming from the archwire-bracket contact dictates both deposition of corrosion products on the surface and the ion release from orthodontic archwires. Moreover, the current set of experiments demonstrated that the actual intraoral conditions the orthodontic archwires become exposed to can be successfully simulated in terms of both physical and chemical conditions through static immersion experiments when archwire-bracket contact is provided.

\section{Conclusions}

The biocompatibility of commercial Nickel-Titanium (NiTi) orthodontic archwires was evaluated through ex situ experiments incorporating realistic chemical and mechanical contact conditions the archwires become subject to during actual intraoral stay. The results indicated that the archwire-bracket contact sites constitute critical regions for the deposition of corrosion products owing to elevated stress concentration, which creates high energy zones around the contact areas. On the other hand, these products prevented significant $\mathrm{Ni}$ or $\mathrm{Ti}$ ion release from the archwires by blocking the cracks formed as a result of SCC in the same areas. Moreover, the results of the experiments involving archwire-bracket contact significantly differed from the experiments where mechanical contact was not provided, such that the former set of experiments successfully simulated the actual intraoral cavity in terms of formation and localization of corrosion products at the archwire-bracket contact sites. Overall, the current study demonstrates that the incorporation of both chemical and mechanical contact conditions of exposure in the actual intraoral cavity is necessary for a reliable biocompatibility experiment.

\section{Acknowledgements}

D. Canadinc acknowledges the financial support by the Turkish Academy of Sciences (TÜBA) within the Outstanding Young Scientist Program (GEBIP). B. Uzer acknowledges the financial support by the Scientific and Technological Research Council of Turkey (TÜBİTAK) within the National Graduate Student Fellowship Program 2211.

\section{References}

1. Nikolai RJ (1997) Orthodontic wire: a continuing evolution. Semin Orthod 3 157-165

2. Duerig T, Pelton A, Sto D (1999) An overview of nitinol medical applications. Mater Sci Eng A 273-275: 149-160.

3. Mani G, Feldman MD, Patel D, Agrawal CM (2007) Coronary stents: a materials perspective. Biomaterials 28: 1689-1710.

4. Bansiddhi A, Sargeant TD, Stupp SI, Dunand DC (2008) Porous NiTi for bone implants: a review. Acta Biomater 4: 773-782.

5. Wang J, Li N, Rao G, Han EH, Ke W (2007) Stress corrosion cracking of NiT in artificial saliva. Dent Mater 23: 133-137.

6. Davidovitch Z, Krishnan V (2009) Role of basic biological sciences in clinical orthodontics: a case series. Am J Orthod Dentofacial Orthop 135: 222-231.

7. Wehrbein H, Göllner P (2007) Skeletal anchorage in orthodontics--basics and clinical application. J Orofac Orthop 68: 443-461.

8. Van Schepdael A, Vander Sloten J, Geris L (2013) Mechanobiological modeling can explain orthodontic tooth movement: three case studies. Biomech 46: 470-477.

9. Toker SM, Canadinc D (2014) Evaluation of Biocompatibility of NiTi Dental Wires: A Comparison of Laboratory Experiments and Clinical Conditions. Mater Sci Eng C 40: 142-147.

10. Miyazaki S, Otsuka K (1989) Development of Shape Memory Alloys. ISIJ International 29: 353-377.

11. Toker SM, Canadinc D, Maier HJ, O Birerc (2014) Evaluation of passive oxide layer formation-biocompatibility relationship in NiTi shape memory alloys: Geometry and body location dependency. Mater Sci Eng C Mater Biol Appl 36: $118-29$.

12. House K, Sernetz F, Dymock D, Sandy JR, Ireland AJ (2008) Corrosion of orthodontic appliances--should we care? Am J Orthod Dentofacial Orthop 133: 584-592.
13. Liu J-K, Lee T-M, Liu I-H (2011) Effect of loading force on the dissolution behavior and surface properties of nickel-titanium orthodontic archwires in artificial saliva. Am J Orthod Dentofacial Orthop 140: 166-176.

14. Bourauel C, Fries T, Drescher D, Plietsch R (1998) Surface roughness of orthodontic wires via atomic force microscopy, laser specular reflectance, and profilometry. Eur J Orthod 20: 79-92.

15. Prymak O, Klocke A, Kahl-Nieke B, M. Epple (2004) Fatigue of orthodontic nickel-titanium (NiTi) wires in different fluids under constant mechanical stress. Mater Sci Eng A 378: 110-114.

16. Milheiro A, Kleverlaan C, Muris J, Feilzer A, Pallav P (2012) Nickel release from orthodontic retention wires-the action of mechanical loading and $\mathrm{pH}$ Dent Mater 28: 548-553.

17. Pacheco MR, Jansen WC, Oliveira DD (2012) The role of friction in orthodontics. Dental Press J Orthod 17: 170-177.

18. Inami T, Tanimoto $Y$, Yamaguchi M, Shibata $Y$, Nishiyama N et al. (2016) Surface topography, hardness, and frictional properties of GFRP for esthetic orthodontic wires. J Biomed Mater Res B Appl Biomater 104: 88-95.

19. lijima M, Muguruma T, Brantley WA, Mizoguchi I (2011) Comparisons of nanoindentation, 3-point bending, and tension tests for orthodontic wires. Am J Orthod Dentofacial Orthop 140: 65-71.

20. Doshi UH, Bhad-Patil WA (2011) Static frictional force and surface roughness of various bracket and wire combinations. Am J Orthod Dentofacial Orthop 139: $74-79$

21. Kusy RP, Whitley JQ (1997) Friction between different wirebracketconfigurations and materials. Semin Orthod 3: 166-177.

22. Al-Waheidi EM (1995) Allergic reaction to nickel orthodontic wires: a case report. Quintessence Int 26: 385-387.

23. Grimsdottir MR, Hensten-Pettersen A (1997) Surface analysis of nickeltitanium archwire used in vivo. Dent Mater 13: 163-167.

24. Huang H-H (2007) Variation in surface topography of different NiTi orthodontic archwires in various commercial fluoride-containing environments. Dent Mater 23: 24-33.

25. Pun DK, Berzins DW (2008) Corrosion behavior of shape memory, superelastic, and nonsuperelastic nickel-titanium-based orthodontic wires at various temperatures. Dent Mater 24: 221-227.

26. Heßing C, Frenzel J, Pohl M, S. Shabalovskaya (2008) Effect of martensitic transformation on the performance of coated NiTi surfaces. Mater Sci Eng A 486: 461-469.

27. Mockers O, Deroze D, Camps J (2002) Cytotoxicity of orthodontic bands, brackets and archwires in vitro. Dent Mater 18: 311-317.

28. Lee T-H, Wang C-C, Huang T-K, Li-Kai Chen, Ming-Yung Chou, et al. (2009) Corrosion resistance of titanium-containing dental orthodontic wires in fluoride-containing artificial saliva. J Alloys Compd 488: 482-489.

29. Li X, Wang J, Han EH, Ke W (2007) Influence of fluoride and chloride on corrosion behavior of NiTi orthodontic wires. Acta Biomater 3: 807-815.

30. Huang HH, Chiu YH, Lee TH, Wu SC, Yang HW, et al. (2003) lon release from $\mathrm{NiTi}$ orthodontic wires in artificial saliva with various acidities. Biomaterials 24 3585-3592.

31. Archwire NH (2014) 3M Unitek Orthodontic Wire Properties - Nitino Archwires 3M Unitek Orthodontic Wire Properties - Nitinol Archwires 3M Unitek Orthodontic Wire Properties - Nitinol Archwires.

32. Brosens V, Ghijselings I, Voet M, Pieter Leemans, Jan Van Humbeeck et al (2012) Transformation Behaviour, Bending Properties and Surface Quality of 22 Commercial Nickel- Titanium Wires: A Batch-to-Batch Evaluation. Br J Med Med Res; 2: 597-620.

33. Al-Hity RR, Kappert HF, Viennot S, Dalard F, Grosgogeat B (2007) Corrosion resistance measurements of dental alloys, are they correlated? Dent Mater 23: $679-687$.

34. Huang R, Han Y (2013) The effect of SMAT-induced grain refinement and dislocations on the corrosion behavior of Ti-25Nb-3Mo-3Zr-2Sn alloy. Mater Sci Eng C Mater Biol Appl 33: 2353-2359.

35. Estrin Y, Ivanova EP, Michalska A, Truong VK, Lapovok R, et al. (2011) Accelerated stem cell attachment to ultrafine grained titanium. Acta Biomater 7: $900-906$

36. Heravi F, Mokhber N, Shayan E (2014) Galvanic Corrosion among Differen Combination of Orthodontic Archwires and Stainless Steel Brackets. J Dent Mater Tech 3: 118-122

37. lijima M, Endo K, Yuasa T, Ohno H, Hayashi K, et al. (2006) Galvanic corrosion behavior of orthodontic archwire alloys coupled to bracket alloys. Angle Orthod 76: 705-711. 